\title{
Genetic and Other Contributions to Alcohol Intake in Rhesus Macaques (Macaca mulatta)
}

\author{
Joseph G. Lorenz, Jeffrey C. Long, Markku Linnoila, David Goldman, Stephen J. Suomi, \\ and J. Dee Higley
}

\begin{abstract}
Background: The etiology of alcoholism and alcohol abuse, like many other complex diseases, is heterogeneous and multifactorial. Numerous studies demonstrate a genetic contribution to variation in the expression of alcohol-related disorders in humans. Over the past decade, nonhuman primates have emerged as a valuable model for some aspects of human alcohol abuse because of their phylogenetic proximity to humans. Long-term, longitudinal studies of rhesus macaques (Macaca mulatta) have provided much insight into environmental influences, especially early life experiences, on alcohol consumption and behavior patterns that characterize alcohol intake later in life. It is not known, however, whether there is a genetic component as well to the variation seen in alcohol consumption in rhesus macaques. A significant genetic component to variation in alcohol consumption in rhesus macaques would show for the first time that like humans, for nonhuman primates additive genetic influences are important. Moreover, their use as a model for alcohol-related disorders in humans would have even greater relevance and utility for designing experiments incorporating the expanding molecular genetics field, and allow researchers to investigate the interaction among the known environmental influences and various genotypes.

Methods: In this study, we investigate factors contributing to variation in alcohol consumption of 156 rhesus macaques collected over 10 years when subjects were adolescent in age, belonging to a single extended pedigree, with each cohort receiving identical early rearing backgrounds and subsequent treatments. To measure alcohol consumption each animal was provided unfettered simultaneous access both to an aspartame-sweetened $8.4 \%$ (v/v) alcohol-water solution, the aspartame-sweetened vehicle, and to water for 1 hour each day during the early afternoon between 13:00 and 15:00 in their home cages for a period of 5 to 7 weeks. We use multiple regression to identify factors that significantly affect alcohol consumption among these animals and a maximum likelihood program (ASReml) that, controlling for the significant factors, estimates the genetic contribution to the variance in alcohol consumption.

Results: Multiple regression analysis identified test cohort and rearing environment as contributing to 57 and $2 \%$, respectively, of the total variance in alcohol consumption. Of the remaining $41 \%$ of the variance about half $(19.8 \%)$ was attributable to additive genetic effects using a maximum likelihood program.

Conclusion: This study demonstrates that, as in humans, there are additive genetic factors that contribute to variation in alcohol consumption in rhesus macaques, with other nongenetic factors accounting for substantial portions of the variance in alcohol consumption, Our findings show the presence of an additive genetic component and suggest the potential utility of the nonhuman primate as a molecular genetics tool for understanding alcohol abuse and alcoholism.
\end{abstract}

Key Words: Heritability, Alcohol Consumption, Additive Genetic Effects.

From the Laboratory of Molecular Biology, Coriell Institute for Medical Research, Camden, New Jersey (JGL); the Department of Human Genetics, and Center for Statistical Genetics, University of Michigan Medical School, Ann Arbor, Michigan (JCL); the Section for the Study of Primate Models of Psychopathology, LCTS, NIAAA, NIH, Poolesville, Maryland (JDH); the Laboratory of Comparative Ethology, NICHD, NIH, Poolesville, Maryland (SJS); and the Laboratory of Neurogenetics, NIAAA, NIH, Rockville, Maryland (DG).

Received for publication May 24, 2004; accepted October 26, 2005.

Reprint requests: Joseph G. Lorenz, Coriell Institute for Medical Research, 403 Haddon Avenue, Camden, NJ 08103; E-mail: jlorenz (a) coriell.umdnj.edu

M. Linnoila is deceased. This manuscript is dedicated to his memory as he contributed to the development of the model in many ways.

Copyright (C) 2006 by the Research Society on Alcoholism.

DOI: $10.1111 /$ j.1530-0277.2006.00044.x
7 XCESSIVE AlCOHOL CONSUMPTION is a fundamental behavior that underlies the development, onset, and maintenance of diverse problems, including accidental injury, birth defects, psychiatric disorders, and addiction. Twin and adoption studies have provided evidence in humans for a heritable component of variation underlying differences in alcohol consumption but the heritability estimates vary widely across studies, anywhere from 0.10 to 0.75 (Clifford et al., 1984; de Castro, 1993; Heath et al., 1991; Heath and Martin, 1994; Kaprio et al., 1987; Reed et al., 1994; Swan et al., 1990). Many of the differences in findings among studies are likely because of differences in study design including the definition of alcohol consumption variables, sample sizes, 
which covariates are included, and whether or not abstainers are analyzed along with drinkers (Grant and Bennett, 2003). However, less tractable factors such as shared environment and genotype by environment interaction may also contribute to differences among studies (Barr et al., 2004b). Moreover, it is becoming clear that different environments modulate genetic effects at times even inhibiting or exaggerating the genetic influence. Because their backgrounds are variable, it is difficult to control environmental factors when studying humans. The environment is more easily controlled in analyses of experimental animals thus allowing for sharper insights into genetic effects.

In our first study investigating alcohol intake in a group of macaques we showed that stress and early parental absence induce alcohol consumption at rates producing frequent intoxication in nonhuman primates (Higley et al., 1991). Since that original report, several cohorts have been tested under more or less similar conditions, allowing us to increase our sample size considerably. With over 150 subjects now tested for alcohol intake, we can for the first time perform complex analyses that elucidate both genetic and environmental influences. It has become clear that independent of early rearing history some individual subjects will consume alcohol in excess. Primates such as the widely studied rhesus macaques are excellent animal models for alcohol-related behaviors in humans. They are close phylogenetic relatives with a complex social structure and an extended period of maturation and parental investment. When offered a palatable solution with an alcohol concentration less than $20 \%$, most monkeys will voluntarily consume enough alcohol to experience pharmacological effects (Higley and Bennett, 1999; Higley et al., 1996b, 1996c; Kraemer and McKinney, 1985). As in humans, monkeys vary considerably in the quantity of alcohol that they consume. Although the amount of alcohol consumed depends on factors such as early experiences, particularly parental absence early in life (Higley and Bennett, 1999), sex, and the animal's previous experience in drug self-administration (Grant and Johanson, 1988), alcohol consumption is generally trait-like in rhesus macaques and remains relatively stable over time (Higley et al., 1991). Alcohol metabolism in macaques is similar to that seen in humans. For example, Green et al. (1999) found that the rate of metabolism was similar to that seen in humans with sex differences in the rate of ethanol elimination in cynomolgus macaques (Macaca fasicularis) that parallels those observed in humans. Moreover, behaviors and neurophysiology that characterize types of human alcoholism have been shown to be present in rhesus macaques that consume alcohol excessively, at rates producing daily intoxication (Higley et al., 1991). As in humans, stress and an impulsive temperament increase the risk for excessive alcohol intake (Higley et al., 1991; Higley et al., 1996b, 1996c). Work by a number of researchers has delineated a wide variety of variables that are responsible for motivating alcohol intake, such as induction procedures and gustatory incentives (Gomez and Meisch, 2003; Vivian et al., 1999), reinforcement (Stewart et al., 2002), and neurochemical and neurophysiological systems that underlie high-alcohol intake (Fahlke et al., 2002; Floyd et al., 2004).

Because alcohol abuse in nonhuman primates has only recently been quantified and its underlying etiological mechanisms studied, there are to our knowledge no systematic overall genetic analyses of individual differences in alcohol consumption patterns. Many experimental treatments applied to rhesus monkeys amplify drinking behavior variation in dimensions that are relevant to human drinking (Higley et al., 1991, 1996b, 1996c). For example, to the extent that human drinking habits are shaped by early experience and parental treatment, imposing rearing differences on animals will mimic a human component of shared family environment. As drinking in humans often occurs in adolescence and early adulthood, a time when the immediate influence of the natal family has waned, the potential effects of modifying rhesus group composition and housing conditions would relate to aspects of individual environment in humans. However, these experimental treatments can serve to amplify environmental variance in experimental animals. They will potentially diminish the importance of genetic differences either by swamping the genetic effects or creating interactions that will reduce the correlations among relatives. The critical question then becomes will genetic effects be detectable in this situation and if so, to what extent are genetic effects present in nonhuman primates, as well as in humans?

In this study, we present data on the etiology of alcohol consumption in 156 rhesus macaques with known pedigrees. A specific goal of this research was to assess the overall genetic contribution to the variation in alcohol consumption. These animals are part of an ongoing longitudinal experimental study on the effects of early rearing experiences and other experimental factors on alcohol consumption and correlated behaviors (Higley et al., 1994). Experiments on these animals have demonstrated that alcohol consumption is augmented as a result of early rearing experiences. For example, on the average, parentally deprived, peer-reared monkeys drink more as adults than monkeys raised by their parents. Unlike most parentally reared subjects, peer-reared subjects often voluntarily drink to the point of intoxication, showing ataxia, stupor, and at times unconsciousness (Higley et al., 1991, 1996b, 1996c). Nevertheless, there are wide individual differences in rates of consumption such that a few mother-reared subjects drink at rates equal to the peer-reared subjects. Conversely, some peer-reared subjects' are resilient to the deleterious effects of peer rearing, showing only modest rates of alcohol consumption. Such findings suggest that other variables such as the drinking setting, social factors, gender, and possibly genes play an important role in determining individual rates of consumption. 
What follows is the first comprehensive assessment of variables that contribute to alcohol consumption in the nonhuman primate. The study was specifically designed to test whether nonhuman primates' alcohol consumption patterns, like human's, are influenced by genetic background. Demonstrating this is a crucial first step in determining whether more specific genetic influences, such as specific neurobiological or biochemical candidate genes contribute to overall alcohol consumption. Moreover, establishing genetic influences is of critical importance in understanding the degree that nonhuman primates can be used as a model for human alcohol abuse and alcoholism and in understanding the parallels and differences between humans and nonhuman primates. Moreover, the joint action of genotypes and environments can be studied in a manner not possible in humans. For example, a recent study in this same population of macaques demonstrated a unique interaction between serotonin transporter genotype and CNS serotonin functioning. A deleterious effect of the less efficient genotype (i.e., carrying the "short" allele) was only phenotypically expressed if the subjects were reared in deleterious environments (Bennett et al., 2002; Champoux et al., 2002; Barr et al., 2003, 2004a, 2004b). Finding an overall genetic effect would increase the probability that such interactions could be studied in the nonhuman primate.

The population of rhesus macaques used in this study is unique and provides several advantages: it is outbred with an average idenity by descent of $1.68 \%$, a measure of pairwise relatedness equivalent to eighth-degree relatives (third cousins), which is sufficiently low to be considered essentially unrelated (Robbins et al. 1997). In addition, the pedigrees are large, the genetic relationships are known for several generations, and the rearing and drinking environments are uniformly manipulated, measured, and highly controlled. The developmental period of the rhesus macaque is extensive, with full adulthood not obtained until subjects are 4 and 5 yeas of age. A major advantage of this long-term study that has allowed us to acquire a relatively large sample is that over the 10-year study period, a uniform treatment protocol has been imposed assuring that each cohort receives identical rearing and experimental manipulations, caging arrangements, and diets. Even variables such as handling, feeding, and day-night light cycles have been held constant. Given these advantages, we have been able to amass a large number of subjects reared under homogeneous conditions, allowing for the first time a study of the role that environmental and quantitative genetic factors play in alcohol consumption in a nonhuman primate. Because the structure of these outbred pedigrees is dominated by unilineal relatives, raised separately in controlled environments, we are able to control for the possibly confounding influences of common family environment while at the same time exploring the effect of extreme differences in early experience that affect alcohol consumption. In addition to the genetic influences, with such a large population and carefully controlled testing conditions, we are able to also better assess the variables which are of most impact when considering situational and developmental influences on excessive alcohol consumption.

\section{MATERIALS AND METHODS}

\section{Animals and Pedigree}

The animals in this study are drawn from a large ongoing longitudinal study investigating genetic and environmental factors affecting neurobiology, behavior, and alcohol consumption (Higley and Linnoila, 1997). Alcohol consumption was measured for 156 (77 males, 79 females) rhesus macaques. Seventy-four of the animals were born at the Harlow Primate Laboratory (HPL) (University of Wisconsin, Madison, WI). Most of the HPL animals $(n=58)$ were born between 1983 and 1986; 10 others were born between 1971 and 1979, and 6 animals were born between 1988 and 1989. The remaining animals $(n=82)$ were born between 1991 and 1994 and tested at the National Institutes of Health Animal Center (NIHAC) at Poolesville, Maryland (see Table 1 for a summary of the characteristics of each test cohort). All of the NIHAC animals tested are descended from HPL ancestors. Founding animals arrived at HPL and NIHAC at different dates and from different locations beginning in the 1950s and were thus unlikely to have been related as they came from distant geographic locations. Thus, the pedigree from which the NIHAC colony was derived consists of unrelated founder males and females. Inbreeding, even with distant kin, is typically prevented by planned matings, and each breeding generation has seen the import of new unrelated males to the breeding program.

Pedigree relationships for the animals in this study were ascertained from colony management records and by genetic parentage testing. Where paternity was uncertain for the HPL animals it was resolved by genotyping offspring, dams, and potential sires for immunogenetic and protein electrophoretic markers (Newman et al., 2002; Rogers et al., 2000). Paternity was established for the NIHAC animals by genotyping offspring, dams, and potential sires for short-tandem repeat (STR) loci. The STRs were amplified by polymerase chain reaction using primer sequences designed to amplify homologous human sequences. A set of STRs that amplified well and was informative for parentage testing in rhesus macaques (Table 2) was identified by screening the Genethon marker set (Dib et al., 1996). Alleles were detected using fluorescent-dye methods with an ABI 373 Prism Sequencer (PE, Foster City, CA). The inbreeding coefficient was computed for each monkey, and the genetic kinship coefficient was computed for all pairs of monkeys using the recursive steps outlined by Lange, 1997.

\section{Rearing Conditions}

After birth animals were assigned to 1 of 4 rearing conditions. Mother-reared (MR, $n=65$ ) subjects were housed with their mother, either in single-caged mother-infant dyads or in a social group containing the mother, other adults, and age-mates. Peer-reared animals (PR, $n=54)$ were immediately removed from their mothers at birth and placed into the neonatal nursery where they received standardized care (Ruppenthal, 1979). At 30 days of age they were placed in a cage with 3 other age-mates with whom they had continuous and sole contact for the next 6 months. Surrogate peer-reared (SPR, $n=19)$ animals received care identical to the peer-reared subjects, except the time spent with same-aged peers was limited to only a few hours each day and they had continuous access to a surrogate. Specifically, from 30 days of life until they were weaned at 7 to 8 months of age, the SPR animals were housed singly in cages containing an inanimate 


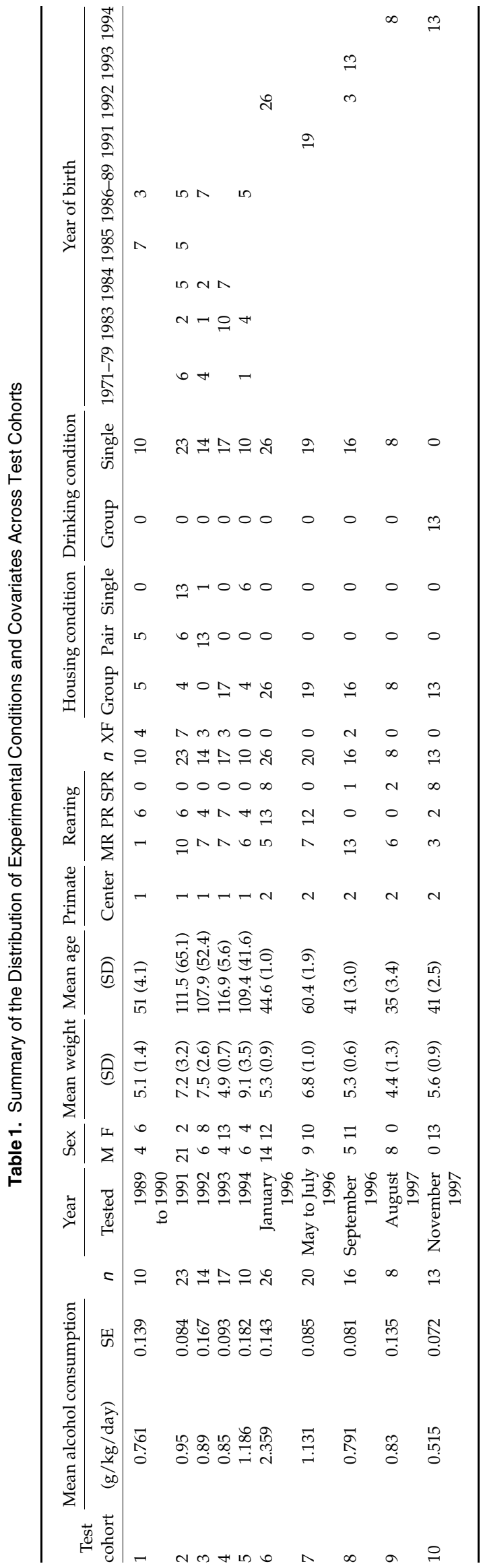

Table 2. STR Loci Used in Paternity Analysis

\begin{tabular}{|c|c|c|c|}
\hline Locus & Primer Pair & Size & $H$ \\
\hline \multirow[t]{2}{*}{ D01S213 } & CATTATCCAAGGTCAGGAGG & 88 to 112 & 0.747 \\
\hline & AGCTGTTAATCCAATCTATGATGTG & & \\
\hline \multirow[t]{2}{*}{ D01S223 } & TAACATGAGCGAATGGACAA & 222 to 256 & 0.667 \\
\hline & CAAGGTTTCACCACAGTTCT & & \\
\hline \multirow[t]{2}{*}{ D01S235 } & CAGCAAGAGTTCATGGGA & 170 to 182 & 0.171 \\
\hline & AACAGTCAATTACAAAATATGTGTG & & \\
\hline \multirow[t]{2}{*}{ D02S144 } & TCTCCCTGACAGACTCTGCG & 166 to 190 & 0.817 \\
\hline & GCTGCATAGGCCGTACTGAG & & \\
\hline \multirow[t]{2}{*}{ D04S243 } & TCAGTCTCTCTTTCTCСTTGCA & 194 to 270 & 0.916 \\
\hline & TAGGAGCCTGTGGTCCTGTT & & \\
\hline \multirow{2}{*}{ D06S284 } & CATGGCTGTCTATCAAACCC & 114 to 118 & 0.560 \\
\hline & AAGCATTTGTGTGGCTCTTG & & \\
\hline \multirow{2}{*}{ D07S650 } & AGGCTGCTTAGCCATAATC & 282 to 308 & 0.797 \\
\hline & CCACTGGTATAAGTACATCAG & & \\
\hline \multirow{2}{*}{ D11S928 } & AAGTGATCCACCTGCCTTG & 258 to 282 & 0.742 \\
\hline & GCCTCTGAGAATTAGTGTCTG & & \\
\hline \multirow{2}{*}{ D12S325 } & GGGCACTATGGTGTCTTCA & 198 to 234 & 0.747 \\
\hline & AGGGCATTGTCTTACTGACTG & & \\
\hline \multirow{2}{*}{ D15S519 } & GGTCAAAGTGGCTGTGTAAGGA & 174 to 196 & 0.838 \\
\hline & TTTAAATGGGTGAATGTATGGTG & & \\
\hline \multirow[t]{2}{*}{ D17S804 } & GCCTGTGCTGCTGATAACC & 152 to 166 & 0.183 \\
\hline & CACTGTGATGAGATGTCATTCC & & \\
\hline \multirow{2}{*}{ D18S537 } & TCCATCTATCTTTGATGTATCTATG & 154 to 178 & 0.650 \\
\hline & AGTTAGCAGACTATGTTAATCAGGA & & \\
\hline \multirow[t]{2}{*}{ D20S114 } & СССТCAGAGGCATTATCCACC & 246 to 258 & 0.633 \\
\hline & TTAACCTAGCCCCATCTTGTGA & & \\
\hline \multirow[t]{2}{*}{ D20S177 } & AGCAATGAGTAAACCTGCCT & 88 to 100 & 0.476 \\
\hline & ССАССТАTССАССТATGGTATG & & \\
\hline \multirow{2}{*}{ D20S189 } & AGCTACACCAGTTGTCAGCG & 296 to 316 & 0.550 \\
\hline & GAATGGATGTGGCATCTTCT & & \\
\hline \multirow[t]{2}{*}{ D22S280 } & GCTCCAGCCTATCAGGATG & 196 to 220 & 0.794 \\
\hline & GATTCCAGATCACAAAACTC & & \\
\hline \multirow[t]{2}{*}{$\mathrm{DM}$} & CTTCCCAGGCCTGCAGTTTGCCCATC & 128 to 137 & 0.223 \\
\hline & GAACGGGGCTCGAAGGGTCCTTGTAC & & \\
\hline
\end{tabular}

All loci are dinucleotide repeats with the exception of DM, a trinucleotide repeat locus, and D4s243 and D18s537, which are tetranucleotide repeat loci.

heated, terry cloth-covered, rocking "surrogate mother" from which the subject received warmth, nutrition, and kinesthetic stimulation. Surrogate peer-reared animals were allowed to socialize in playgroups for a fixed number of hours each day. They were then returned to their home cage where they spent the evening, sleeping alone. These play groups consisted of the same animals each day. Cross-fostered (XF, $n=18)$ animals were removed from their mother at birth and placed on another unrelated, lactating female that had recently given birth and she then raised the infant as her own as in the MR treatment.

\section{Alcohol Consumption}

Animals were tested for differences in voluntary alcohol consumption as described in earlier studies (Higley et al., 1991, 1996b, 1996c). Alcohol consumption rates were measured as grams of alcohol consumed $/ \mathrm{kg}$ body weight $/ \mathrm{d}$ and the average was computed for each animal. To test for alcohol consumption rates, each animal was provided unfettered simultaneous access to an aspartame-sweetened (14 g/gallon) $8.5 \%(\mathrm{v} / \mathrm{v})$ alcohol-water solution, the aspartamesweetened vehicle, as well as water for 1 hour in the early afternoon between 13:00 and 15:00 hours each day in their home cages for a period of 5 to 7 weeks. The animals were not deprived of food or water during the study. During the duration of the study the animals were housed singly $(n=20)$, in pairs $(n=24)$, or in groups $(n=112)$. For the hour in which they were exposed to alcohol, most of the subjects (i.e., Test Cohorts 1 through $9 ; n=144$ ) were separated into 
individual cages. However, some of the subjects (i.e., Test Cohort 10) remained in their intact social group where they were exposed to alcohol in a cage with cage-mates $(n=13)$. In the latter case alcohol consumption was recorded by an automatic dispenser, which could identify individual monkeys by a microchip embedded in their collar. Most of the monkeys were exposed to the alcohol as adolescents or very young adults. The ages at which animals were exposed to alcohol differed between the HPL and the NIHAC. The HPL subjects were older (range 45 to 244 months, median 78 months) than the NIHAC subjects, which were tested as adolescents (range 32 to 63 months, median 44 months). The animals at both facilities were tested in cohort groups that ranged in size from 8 to 26 individuals. The test cohorts were composed of animals born during the same breeding season and thus were of approximately the same age.

\section{Statistical Analysis}

Single and multiple regression were performed to determine which experimental treatments and covariates contributed significantly to nonheritable differences in alcohol consumption among animals. Nine variables were analyzed: sex, weight at the time of alcohol consumption $(\mathrm{kg})$, age at the time of alcohol consumption (months), birth year, primate center (HPL, NIHAC), housing condition (group, pair, single), drinking condition (single, group), rearing condition (MR, PR, SPR, XF), and test cohort. Categorical variables were entered into the regression analyses using indicator variables as described by Neter et al. (1985). Multiple regression analysis served 2 purposes here. First, it identified which specific categories of the polychotomous treatments and covariates differed with respect to alcohol consumption. Second, it was used to identify a subset of covariates and treatments that best accounted for differences in drinking. This was necessary because the covariates and treatments were not independent; e.g., age and weight are significantly interrelated.

The phenotypic variance for alcohol consumption was partitioned into additive genetic and environmental components using the ASReml program (Gilmour et al., 1998). The ASReml is well suited for multigenerational animal breeding situations such as ours because it accommodates large complex pedigrees with multiple matings and inbreeding. The ASReml uses the average information algorithm to obtain maximum likelihood estimates of variance components and their standard errors under a variety of animal models while controlling for specified covariates and fixed effects. The appropriate fixed effects and covariates for the analysis of alcohol consumption in these rhesus monkeys were identified by the multiple regression analysis described above. Narrow-sense heritability $\left(h^{2}\right)$ was estimated as the ratio

$$
\hat{h}^{2}=\frac{\hat{\sigma}_{a}^{2}}{\hat{\sigma}_{a}^{2}+\hat{\sigma}_{e}^{2}},
$$

where $\hat{\sigma}_{a}^{2}$ and $\hat{\sigma}_{e}^{2}$ are estimates of the additive genetic and environmental variance components, respectively. The null hypothesis $h^{2}=0$ was testing using a log likelihood ratio chi-squared statistic comparing a model with both additive genetic and environmental variance to a model with environmental variance alone.

\section{RESULTS}

\section{Pedigree}

The 156 tested animals belong to a single extended pedigree. The complete genealogy of the 156 animals tested in this study includes 396 untested ancestors. The average genetic kinship among pairs of tested animals was 0.018 ,
Table 3. Summary of Pedigree Relationships

\begin{tabular}{lc} 
Relationship & $N$ (pairs) \\
\hline Father/offspring & 107 \\
Mother/offspring & 58 \\
Full sibling & 19 \\
Maternal half-sibling & 79 \\
Paternal half-sibling & 452
\end{tabular}

i.e., roughly second cousins. Only 21 animals were inbred, the average inbreeding coefficient among these inbred animals was 0.067 , i.e., resulting from first cousin unions. The genealogical relationships among the 156 tested animals are summarized in Table 3. As there is a large preponderance of unilineal relatives, it was unfeasible to estimate the extent of dominance variance or the broad sense heritability.

\section{Statistical Results}

Alcohol consumption $(\mathrm{g} / \mathrm{kg} / \mathrm{d})$ differed among animals depending on standard covariates and experimental treatments (Table 4). The sex difference in alcohol consumption relative to body weight $(\mathrm{g} / \mathrm{kg} / \mathrm{d})$ was not statistically significant, but males drank slightly more than females $(p=0.104)$. On average, within the narrow adolescent-young adult range we tested, older monkeys consumed more than younger monkeys $(p=0.034)$, and monkeys that weighed more consumed more per kilogram of body weight than monkeys that weighed less $(p=0.024)$. Alcohol consumption was greater at NIHAC than HPL $(p<0.001)$. There was also a birth cohort difference, with the heaviest drinkers being born in the years 1991 and $1992(p<0.001)$. Relative to alcohol consumption in the remaining cohorts, test cohort 6 consumed significantly more and cohort 10 consumed significantly less than the average. In terms of living contributions, there was no apparent difference in alcohol consumption among monkeys housed singly, in pairs, or in larger groups $(p=0.310)$. In terms of testing conditions, the animals which were offered alcohol in the group situation (i.e., Test Cohort 10) drank significantly less than the animals that were offered alcohol when alone $(p=0.001)$. As shown elsewhere (Higley et al., 1996b, 1996c), early rearing condition significantly affected the quantity of alcohol consumed at maturity. Subjects reared with their biological mother (i.e., mother-reared animals) drank significantly less $(p=0.001)$ than cross-fostered, peer-reared, or surrogate peer-reared animals.

\section{Stepwise Regression Analyses}

As the 9 covariates and experimental treatments were not statistically independent, stepwise multiple regression was used to find a subset of variables that explained a high percentage of the variance and eliminated redundancy 
Table 4. Mean Alcohol Consumption for Levels of Each Experimental Treatment and Standard Covariate and the Results of the Simple Regression Analysis within each Treatment and Covariate

\begin{tabular}{|c|c|c|c|c|}
\hline Variable & $n$ & $\begin{array}{l}\text { Mean alcohol } \\
\text { consumption, } \\
\text { g/kg/d (SE) }\end{array}$ & $\mathrm{F}(d f)$ & $p$ Value \\
\hline Sex & & & $2.67(1,154)$ & 0.104 \\
\hline Male & 77 & $1.24(0.09)$ & & \\
\hline Female & 79 & $1.04(0.08)$ & & \\
\hline Age & 156 & $\beta=-0.003(0.001)$ & $4.59(1,154)$ & 0.034 \\
\hline Weight & 156 & $\beta=-0.060(0.027)$ & $5.17(1,154)$ & 0.024 \\
\hline Primate center & & & $11.86(1,154)$ & $<0.001$ \\
\hline HPL & 74 & $0.93(0.06)$ & & \\
\hline NIHAC & 82 & $1.33(0.10)$ & & \\
\hline Birth year & & & $18.09(8,147)$ & $<0.001$ \\
\hline$<1983$ & 10 & $0.66(0.09)$ & & \\
\hline 1983 & 17 & $0.89(0.13)$ & & \\
\hline 1984 & 14 & $0.97(0.10)$ & & \\
\hline 1985 & 12 & $0.98(0.14)$ & & \\
\hline 1986-1989 & 21 & $1.03(0.12)$ & & \\
\hline 1991 & 19 & $1.13(0.09)$ & & \\
\hline 1992 & 29 & $2.18(0.16)$ & & \\
\hline 1993 & 13 & $0.82(0.10)$ & & \\
\hline 1994 & 21 & $0.63(0.07)$ & & \\
\hline Test cohort & & & $23.41(9,146)$ & $<0.001$ \\
\hline 1 & 10 & $0.76(0.14)$ & & \\
\hline 2 & 23 & $0.95(0.08)$ & & \\
\hline 3 & 14 & $0.89(0.17)$ & & \\
\hline 4 & 17 & $0.85(0.09)$ & & \\
\hline 5 & 10 & $1.19(0.18)$ & & \\
\hline 6 & 26 & $2.36(0.14)$ & & \\
\hline 7 & 19 & $1.13(0.09)$ & & \\
\hline 8 & 16 & $0.79(0.08)$ & & \\
\hline 9 & 8 & $0.83(0.14)$ & & \\
\hline 10 & 13 & $0.52(0.07)$ & & \\
\hline Rearing condition & & & $5.53(3,152)$ & 0.001 \\
\hline Mother reared & 65 & $0.89(0.06)$ & & \\
\hline Cross fostered & 18 & $1.07(0.10)$ & & \\
\hline Peer reared & 54 & $1.34(0.10)$ & & \\
\hline Surrogate peer reared & 19 & $1.48(0.29)$ & & \\
\hline Drinking condition & & & $10.77(2,153)$ & $<0.001$ \\
\hline Single & 104 & $1.32(0.13)$ & & \\
\hline Group & 13 & $0.98(0.22)$ & & \\
\hline Housing condition & & & $1.18(2,153)$ & 0.31 \\
\hline Group & 112 & $1.20(0.08)$ & & \\
\hline Pair & 24 & $1.00(0.11)$ & & \\
\hline Single & 20 & $0.99(0.12)$ & & \\
\hline
\end{tabular}

$\mathrm{HPL}=$ Harlow Primate Laboratory; NIHAC = National Institutes of Health Animal Center.

of information. This analysis identified 2 statistically significant variables: Test Cohort and rearing condition. Specifically, Test Cohort 6, born in 1992 and tested in January 1996 drank the most $(\beta=1.49 \pm 0.11, p<0.001)$. Drinking was also elevated in Test Cohort 5 , born before

Table 5. Results of the Multiple Regression Analysis for Alcohol Consumption $(\mathrm{g} / \mathrm{kg} / \mathrm{d})$

\begin{tabular}{lrrrc}
\hline Variable & \multicolumn{1}{c}{$\beta(\mathrm{SE})$} & \multicolumn{1}{c}{$\boldsymbol{F}$} & $p$ value & Change in $r^{2}$ \\
\hline Intercept & $0.90(0.06)$ & & & \\
Test Cohort 6 & $1.49(0.11)$ & 179.7 & 0.000 & 0.54 \\
Test Cohort 7 & $0.33(0.12)$ & 6.2 & 0.014 & 0.02 \\
Mother reared & $-0.19(0.08)$ & 5.5 & 0.021 & 0.02 \\
Test Cohort 5 & $0.44(0.19)$ & 5.4 & 0.022 & 0.01 \\
\hline
\end{tabular}

Table 6. Models for Variance of Alcohol Consumption ( $/ \mathrm{kg} / \mathrm{d})$ After Correcting for Experimental Treatments and Standard Covariates

\begin{tabular}{lcc}
\hline & \multicolumn{2}{c}{ Model estimates $( \pm \mathrm{SE})$} \\
\cline { 2 - 3 } Parameter & Environment & Genetic +environment \\
\hline$\sigma_{\mathrm{E}}^{2}$ & $0.206^{\mathrm{a}}$ & $0.114 \pm 0.034$ \\
$\sigma_{\mathrm{A}}^{2}$ & - & $0.111 \pm 0.045$ \\
$h^{2}$ & - & $0.495 \pm 0.165$ \\
$-2 \mathrm{LnL}$ & -29.230 & -43.715 \\
\hline
\end{tabular}

The comparison of models reveals $\chi^{2}=-29.230-(-43.715)=$ 14.485 with $1 d f$ which is statistically significant $(p=0.0001)$.

${ }^{a}$ No standard error was computed for $\sigma_{\mathrm{E}}^{2}$ by ASReml.

1989 and tested in $1994(\beta=0.44 \pm 0.19, p=0.022)$ and in test cohort 7, born in 1991 and tested May to July $1996(\beta=0.33 \pm 0.12, p<0.014)$. Mother-reared animals drank significantly less than animals in other rearing treatments $(\beta=-0.19 \pm 0.08, p=0.021)$. Taken together, these variables accounted for $\sim 60 \%$ of the interindividual variation in alcohol consumption (Table 5).

\section{Heritability Analyses}

The heritability of alcohol consumption was estimated to be $0.495 \pm 0.165$ when test cohort and rearing condition were entered in the model as covariates (Table 6). The log likelihood chi-squared generated by comparing the model with additive genetic and environmental effects to a purely environmental model indicates that the heritability is significantly different from zero $\left(\chi^{2}=14.49, d f=1\right.$, $p<0.0001)$. As $59 \%$ of the observed variation $(57 \%$ accounted by test cohort, $2 \%$ by rearing condition) in alcohol consumption is accounted for by 2 covariates the heritability analysis indicates that additive genetic variation among the subjects accounts for $49.5 \%$ of the remaining $40 \%$ of the variation. Thus additive genetic variation accounts for $\sim 19.8 \%$ of the total observed variation among animals in alcohol consumption in the HPL/NIHAC colonies.

\section{DISCUSSION}

Our data show that as in human alcohol consumption, there is a large genetic contribution in nonhuman primate alcohol consumption. To test this, we have partitioned the variance for alcohol consumption in captive rhesus macaques into heritable and nonheritable components. Alcohol consumption was measured in 156 animals housed at 2 primate facilities. All of the animals belonged to a single-extended pedigree. The nonheritable factors investigated included test cohort, birth year, primate center, maternal rearing treatment, and group composition while drinking. Age, sex, and body weight were also investigated as nonheritable covariates in the analysis. Additive genetic effects were calculated using pedigree likelihood methods. Four main sources of variation in alcohol consumption were identified after taking into 
account statistical confounding among the various nonheritable factors. The largest source of variation, accounting for $57 \%$ of the total, was attributed to test cohort. With cohort controlled, rearing environment, which was experimentally manipulated, surprisingly accounted for only $2 \%$ of the variance. With these variables controlled, additive genetic effects accounted for about $50 \%$ of the remaining variance. Additive genetic effects accounted for $19.8 \%$ of the total variation in alcohol consumption, and the remaining $20.2 \%$ of variance was attributed to residual environment that could not be accounted for despite the rigorous laboratory setting.

Test cohort emerged from the stepwise regression analysis as the only variable that was neither genetic nor an experimental treatment that was important to alcohol consumption. Test Cohorts 7, 8, and 9 drank significantly more than all other test cohorts. Once this source of variance was accounted for, the differences between primate centers, birth years, ages, and weights were no longer statistically significantly. This result was perplexing because test cohort differences are the least tangible of all the nonheritable variables tested. The rearing conditions are tightly controlled, with an identical protocol used each year, and although different technicians were involved in the data collection, the same supervisors were present maintaining identical experimental control. It is reminiscent of a recent demonstration of differences among 3 laboratories for measurements of behavioral phenotypes, including alcohol preference, in mice. These differences were manifest despite rigorous efforts to standardize experimental and handling procedures (Crabbe et al., 1999).

Rhesus macaques raised by their biological mothers drank significantly less than did those raised in adult absent peer groups or by their foster mothers. In humans, early experience and the effects of mothering contribute to family environment, which can be confounded with shared genes. The present research has the advantage of demonstrating independently the potential for both genetics and factors such as mothering, which will lead to correlated family environment. The rearing treatments administered here constitute an extreme manipulation of the relationship between rhesus macaque mother and child and routinely produce higher average consumption rates in the peer-reared and surrogate-peer-reared offspring that exceed those of the offspring reared by their biological parents. Across studies, the contribution of early parental absence on high-alcohol intake is one of our most replicated studies. Yet when the cohorts are aggregated, rearing accounts for only about $3 \%$ of the overall variance, far less than we have seen in other studies where peer-reared subjects drink about double the amount of alcohol of the mother-reared subjects, with peer-reared subjects averaging more than a gram per kilogram per hour and consuming $2 \mathrm{~g} / \mathrm{h}$ in many individual cases (Barr et al., 2003, 2004b; Higley et al., 1991, 1996a, 1996b). It is therefore surprising that the variance attributed to rearing condition was only one-sixth that of additive genes. It is also surprising, given that this is one of our most robust and replicated findings (Fahlke et al., 2000; Higley et al., 1991, 1996a, Higley and Suomi, 1996a, Kraemer and McKinney, 1985). Post hoc analyses of the data show that one of the effects of the cohort variable is that in the years there is low consumption, it is the animals reared without adults whose consumption patterns are most affected. Further post hoc analysis of individual cohorts show that among only some of the years is there a statistically significant difference between mother- and peer-reared subjects, and among the cohorts where such differences are extant, the average rate of consumption for both the mother- and peer-reared subjects is greater, but in years when a cohorts' consumption is diminished, the early rearing experience is typically not present. This suggests a potential threshold effect that must be achieved for such rearing effects to be present. Hence, it may be that the cohort variable modulates the effect of rearing in some unknown manner, reducing both the overall rate of consumption and ultimately the contribution of early rearing experience.

Previous studies have postulated that the higher rate of alcohol consumption in the peer-reared subjects is largely a result of adult parental absence. However, somewhat surprisingly the current results show that the infants that were fostered to an unrelated female also increased their alcohol consumption, and suggest that it is the absence of the biological mother rather than the absence of adults that produces high-alcohol intake later in life. We interpret this result with some caution, however, as the offspring that were fostered to other females were overrepresented by some fathers and cohorts. Thus, paternal genetic influences may have confounded this analysis. Alternatively, studies in human children suggest that because they have similar genes, biological parents posses temperaments that are conducive to what is called a "goodness-of-fit" between the temperament of the child and the parent, resulting in less parent-offspring conflict (Mangelsdorf and Frosch, 1999). It is possible that in the absence of the biological parents to rear the subjects, the temperamental fit results in less harmonious early relations, resulting in more negative developmental outcomes. Additional data from the offspring of other fathers are currently being collected to address this question. Our model makes it is clear, however, that in terms of genetic contributions, mothers and fathers contributed equally to the genetic variance seen in alcohol consumption.

The additive genetic effects accounted for $49.5 \pm 16.5 \%$ of the variance of alcohol consumption in these rhesus macaques after accounting for the effects of test cohort and rearing condition. This estimate was based on all relationships stipulated by the full pedigree. It is worth noting that father-child and paternal half-sibling relationships (Table 3) dominate the genetic information in this pedigree. These relationships are nearly unaffected by 
shared-environmental factors. For example, the male rhesus monkey plays virtually no active part in rearing his offspring either in the wild or in our experimental setting. Moreover, half-siblings sharing the same father are raised separately and are frequently assigned to different rearing treatments. Nonetheless, this pedigree contains very few bilineal relatives, such as full siblings, and it is uninformative for detecting variance owing to the effects of dominance or epistasis (Falconer and MacKay, 1996). We have not attempted to estimate gene-by-environment interactions from the correlations between relatives because very large numbers of relative pairs are necessary for this purpose. However, the additive genetic variance would be diminished in the presence of gene-by-environment interactions and recent findings from our laboratory would make such interactions probable (Barr et al., 2004a, Bennett et al., 2002; Champoux et al., 2002). Nevertheless, the fact that considerable additive genetic variance is present argues against the possibility that gene influences are expressed principally through interactions, even with the extreme nature of our environmental interventions.

The opportunity to experience beverage alcohol is novel for rhesus macaques. Hence, genetic variation underlying the effects of alcohol has not been molded by natural selection. Nevertheless, because nonhuman primates are closely related to humans, it is not unexpected that there is extensive genetic variation underlying differences in alcohol consumption. While the current studies cannot tease out whether the specific genetic contributions are similar to those found in humans, they suggest that biological variation in the disposition to consume alcohol is present in species closely related to us, with wide variation in its tendencies. The amount of genetic variation underlying alcohol consumption in the rhesus may be similar to that for humans. In addition, the rhesus macaques in this study derive from founders obtained at different times and different locations in India and China. Given the relatively large amount of genetic diversity of rhesus macaques compared with humans [mtDNA (Hayasaka et al., 1996; Melnick et al., 1993); microsatellites (Kayser et al., 1995)] it is possible that the genetic variation segregating in our rhesus pedigrees is greater than that present in natural rhesus populations or in human population.

Our findings show that there are genetic contributions to alcohol consumption, at least in the macaque. Subsequent studies should tease out more specifically candidate genes and possible markers that contribute to the genetic influence on alcohol intake. Cloninger predicted impaired central nervous system serotonin and norepinephrine in a subgroup of alcoholics (type 2) with early onset and aggressive behaviors. Higley Linnoila (1997) has shown many parallels between human type 2 alcoholics and rhesus macaques that consume large quantities of alcohol. Cerebral spinal fluid (CSF) concentrations of 5-hydroxyindol-3-ylacetic acid (5-HIAA), the major CNS metabolite of serotonin, are inversely correlated with alcohol con- sumption in adolescent rhesus macaques (Higley and Linnoila, 1997) and humans (LeMarquand et al., 1994). There is evidence for a genetic component of variation in 5-HIAA levels in rhesus macaques (Clarke et al., 1995; Higley et al., 1993). Recent studies have shown that the serotonin transporter genotype contributes to both human (Matsushita et al., 2001; Thompson et al., 2000) and nonhuman primate alcohol consumption (Barr et al., 2003). To the extent that an impaired central serotonin system contributes to excessive alcohol consumption, there are a number of other recently discovered serotonin genes that have been investigated in the macaque. It will be worthwhile to investigate genetic variation in the serotonergic and other potential systems of the rhesus in relation to the genetic variance in alcohol consumption.

It is unlikely that all the alleles affecting alcohol consumption in rhesus macaques are homologous to those affecting alcohol consumption in humans. Environments differ between the two species as well. Nevertheless, recent studies show good harmony between the macaque and human genome for the genes that have been assessed in both species (Bennett et al., 2002; Lesch et al., 1997). Thus the rhesus macaque may serve as a valuable model that will be useful for identifying genetic loci or pathways that are important in both species. The demonstration of a significant component of additive genetic variation in the rhesus monkey is important in this light, and the demonstration of heritability suggests that alcohol consumption in the rhesus macaque could be manipulated by selective breeding, thus allowing even more powerful investigations of gene-environment interactions.

\section{ACKNOWLEDGEMENT}

The authors wish to thank Alan Dodson, Anne Sponberg, Ted King, Todd Graham, Steven Lindell, and Courtney Shannon for their help and assistance in data collection and assays. This research was supported (in part) by the Intramural Research Program of the NIH, National Institute of Child Health and Development.

\section{REFERENCES}

Barr CS, Newman TK, Becker ML, Champoux M, Lesch KP, Suomi SJ, Goldman D, Higley JD (2003) Serotonin transporter gene variation is associated with alcohol sensitivity in rhesus macaques exposed to early-life stress. Alcohol Clin Exp Res 27:812-817.

Barr CS, Newman TK, Lindell S, Becker ML, Shannon C, Champoux M, Suomi SJ, Higley JD (2004a) Early experience and sex interact to influence limbic-hypothalamic-pituitary-adrenal-axis function after acute alcohol administration in rhesus macaques (Macaca mulatta). Alcohol Clin Exp Res 28:1114-1119.

Barr CS, Newman TK, Lindell S, Shannon C, Champoux M, Lesch KP, Suomi SJ, Goldman D, Higley JD (2004b) Interaction between serotonin transporter gene variation and rearing condition in alcohol preference and consumption in female primates. Arch Gen Psychiatry 61:1146-1152.

Bennett AJ, Lesch KP, Heils A, Long JC, Lorenz JG, Shoaf SE, Champoux M, Suomi SJ, Linnoila MV, Higley JD (2002) Early 
experience and serotonin transporter gene variation interact to influence primate CNS function. Mol Psychiatry 7:118-122.

Champoux M, Bennett A, Shannon C, Higley JD, Lesch KP, Suomi SJ (2002) Serotonin transporter gene polymorphism, differential early rearing, and behavior in rhesus monkey neonates. Mol Psychiatry 7:1058-1063.

Clarke AS, Kammerer CM, George KP, Kupfer DJ, McKinney WT, Spence MA, Kraemer GW (1995) Evidence for heritability of biogenic amine levels in the cerebrospinal fluid of rhesus monkeys. Biol Psychiatry 38:572-577.

Clifford CA, Hopper JL, Fulker DW, Murray RM (1984) A genetic and environmental analysis of a twin family study of alcohol use, anxiety, and depression. Genet Epidemiol 1:63-79.

Crabbe JC, Wahlsten D, Dudek BC (1999) Genetics of mouse behavior: interactions with laboratory environment. Science 284:1670-1672.

de Castro JM (1993) A twin study of genetic and environmental influences on the intake of fluids and beverages. Physiol Behav 54:677-687.

Dib C, Faure S, Fizames C, Samson D, Drouot N, Vignal A, Millasseau P, Marc S, Hazan J, Seboun E, Lathrop M, Gyapay G, Morissette J, Weissenbach J (1996) A comprehensive genetic map of the human genome based on 5,264 microsatellites. Nature 380:152-154.

Fahlke C, Garpenstrand H, Oreland L, Suomi SJ, Higley JD (2002) Platelet monoamine oxidase activity in a nonhuman primate model of type 2 excessive alcohol consumption. Am J Psychiatry 159:2107.

Fahlke C, Lorenz JG, Long J, Champoux M, Suomi SJ, Higley JD (2000) Rearing experiences and stress-induced plasma cortisol as early risk factors for excessive alcohol consumption in nonhuman primates. Alcohol Clin Exp Res 24:644-650.

Falconer DS, MacKay TF (1996) Introduction to Quantitative Genetics. Addison-Wesley, Boston, MA.

Floyd DW, Friedman DP, Daunais JB, Pierre PJ, Grant KA, McCool BA (2004) Long-term ethanol self-administration by cynomolgus macaques alters the pharmacology and expression of GABAA receptors in basolateral amygdala. J Pharm Exp Thera 311:1071-1079.

Gilmour AR, Cullis BR, Welham SJ, Thompson R (1998) ASReml [home page on the Internet]. VSL International Ltd., Herts, UK. Available from: http://www.vsn-intl.com/ASReml/index.htm

Gomez KA, Meisch RA (2003) Relation between choice of ethanol concentration and response rates under progressive- and fixed-ratio schedules: studies with rhesus monkeys. Psychopharmacology (Berl) 170:1-8.

Grant KA, Bennett AJ (2003) Advances in nonhuman primate alcohol abuse and alcoholism research. Pharmacol Ther 100:235-255.

Grant KA, Johanson CE (1988) Oral ethanol self-administration in freefeeding rhesus monkeys. Alcohol Clin Exp Res 12:780-784.

Green KL, Szeliga KT, Bowen CA, Kautz MA, Azarov AV, Grant KA (1999) Comparison of ethanol metabolism in male and female cynomolgus macaques (Macaca fascicularis). Alcohol Clin Exp Res 23:611-616.

Hayasaka K, Fujii K, Horai S (1996) Molecular phylogeny of macaques: implications of nucleotide sequences from an 896-base pair region of mitochondrial DNA. Mol Biol Evol 13:1044-1053.

Heath AC, Martin NG (1994) Genetic influences on alcohol consumption patterns and problem drinking: results from the Australian NH\&MRC twin panel follow-up survey. Ann N Y Acad Sci 708: $72-85$.

Heath AC, Meyer J, Jardine R, Martin NG (1991) The inheritance of alcohol consumption patterns in a general population twin sample. II. Determinants of consumption frequency and quantity consumed. J Stud Alcohol 52:425-433.

Higley JD, Bennett AJ (1999) Central nervous system serotonin and personality as variables contributing to excessive alcohol consumption in non-human primates. Alcohol Alcohol 34:402-418.

Higley JD, Hasert MF, Suomi SJ, Linnoila M (1991) Nonhuman primate model of alcohol abuse: effects of early experience, personality, and stress on alcohol consumption. Proc Natl Acad Sci U S A 88: $7261-7265$.
Higley JD, Linnoila M (1997) A nonhuman primate model of excessive alcohol intake: personality and neurobiological parallels of type I- and type II-like alcoholism, in Recent Developments in Alcoholism. Vol. 13. Alcoholism and Violence (Galanter M ed), pp 191-219. Plenum Press, New York

Higley JD, Linnoila M, Suomi SJ (1994) Ethological contributions: experiential and genetic contributions to the expression and inhibition of aggression in primates, in Handbook of Aggressive and Destructive Behavior in Pyschiatric Patients (Hersen M, Ammerman RT, Sisson LA eds), pp 17-32. Plenum Press, New York.

Higley JD, Mehlman PT, Poland RE, Taub DM, Vickers J, Suomi SJ, Linnoila M (1996a) CSF testosterone and 5-HIAA correlate with different types of aggressive behaviors. Biol Psychiatry 40:1067-1082.

Higley JD, Suomi SJ (1996a) Effect of reactivity and social competence on individual responses to severe stress in children: investigations using nonhuman primates, in Intense Stress and Mental Disturbance in Children (Pfeffer CR ed), pp 1-69. American Psychiatric Press, Inc., Washington, DC.

Higley JD, Suomi SJ, Linnoila M (1996b) A nonhuman primate model of type II alcoholism? Part 2. Diminished social competence and excessive aggression correlates with low cerebrospinal fluid 5-hydroxyindoleacetic acid concentrations. Alcohol Clin Exp Res 20:643-650.

Higley JD, Suomi SJ, Linnoila M (1996c) A nonhuman primate model of type II excessive alcohol consumption? Part 1. Low cerebrospinal fluid 5-hydroxyindoleacetic acid concentrations and diminished social competence correlate with excessive alcohol consumption. Alcohol Clin Exp Res 20:629-642.

Higley JD, Thompson WW, Champoux M, Goldman D, Hasert MF, Kraemer GW, Scanlan JM, Suomi SJ, Linnoila M (1993) Paternal and maternal genetic and environmental contributions to cerebrospinal fluid monoamine metabolites in rhesus monkeys (Macaca mulatta). Arch Gen Psychiatry 50:615-623.

Kaprio J, Koskenvuo M, Langinvainio H, Romanov K, Sarna S, Rose RJ (1987) Genetic influences on use and abuse of alcohol: a study of 5638 adult finnish twin brothers. Alcohol Clin Exp Res 11: 349-356.

Kayser M, Nurnberg P, Bercovitch F, Nagy M, Roewer L (1995) Increased microsatellite variability in Macaca mulatta compared to humans due to a large scale deletion/insertion event during primate evolution. Electrophoresis 16:1607-1611.

Kraemer GW, McKinney WT (1985) Social separation increases alcohol consumption in rhesus monkeys. Psychopharmacology 86:182-189.

Lange K (1997) Mathematical and Statistical Methods for Genetic Analysis. Springer Verlag, New York.

LeMarquand D, Pihl RO, Benkelfat C (1994) Serotonin and alcohol intake, abuse, and dependence: clinical evidence. Biol Psychiatry 36:326-337.

Lesch KP, Meyer J, Glatz K, Flugge G, Hinney A, Hebebrand J, Klauck S, Poustka F, Poustka A, Bengel D, Mossner R, Riedere P, Heils A (1997) The 5-HT transporter gene-linked polymorphic region (5HTTLPR) in evolutionary perspective: alternative biallelic variation in rhesus monkeys. Rapid communication. J Neural Transm 104:1259-1266.

Mangelsdorf S, Frosch C (1999) Temperament and attachment: one construct or two? Adv Child Dev Behav 27:181-220.

Matsushita S, Yoshino A, Murayama M, Kimura M, Muramatsu T, Higuchi S (2001) Association study of serotonin transporter gene regulatory region polymorphism and alcoholism. Am J Med Genet 105:446-450.

Melnick DJ, Hoelzer GA, Absher R, Ashley MV (1993) mtDNA diversity in rhesus monkeys reveals overestimates of divergence time and paraphyly with neighboring species. Mol Biol Evol 10:282-295.

Neter J, Wasserman W, Kutner MH (1985) Applied Linear Statistical Models: Regression, Analysis of Variance, and Experimental Designs. Irwin, Homewood, IL.

Newman TK, Fairbanks LA, Pollack D, Rogers J (2002) Effectiveness of human microsatellite loci for assessing paternity in a captive 
colony of vervets (Chlorocebus aethiops sabaeus). Am J Primatol 56:237-243.

Reed T, Slemenda CW, Viken RJ, Christian JC, Carmelli D, Fabsitz RR (1994) Correlations of alcohol consumption with related covariates and heritability estimates in older adult males over a 14- to 18-year period: the NHLBI Twin Study. Alcohol Clin Exp Res 18:702-710.

Robin RW, Chester B, Rasmussen JK, Jaranson JM, Goldman D (1997) Prevalence and characteristics of trauma and posttraumatic stress disorder in a southwestern American Indian community. Am J Psychiatry 154:1582-1588.

Rogers J, Mahaney MC, Witte SM, Nair S, Newman D, Wedel S, Rodriguez LA, Rice KS, Slifer SH, Perelygin A, Slifer M, PalladinoNegro P, Newman T, Chambers K, Joslyn G, Parry P, Morin PA (2000) A genetic linkage map of the baboon (Papio hamadryas) genome based on human microsatellite polymorphisms. Genomics 67:237-247.
Ruppenthal GC (1979) Nursery Care of Nonhuman Primates (Ruppenthal GC ed), pp 165-185. Plenum Press, New York.

Stewart RB, Wang NS, Bass AA, Meisch RA (2002) Relative reinforcing effects of different oral ethanol doses in rhesus monkeys. J Exp Anal Behav 77:49-64.

Swan GE, Carmelli D, Rosenman RH, Fabsitz RR, Christian JC (1990) Smoking and alcohol consumption in adult male twins: genetic heritability and shared environmental influences. J Subst Abuse 2: $39-50$.

Thompson MD, Gonzalez N, Nguyen T, Comings DE, George SR, O'Dowd BF (2000) Serotonin transporter gene polymorphisms in alcohol dependence. Alcohol 22:61-67.

Vivian JA, Higley JD, Linnoila M, Woods JH (1999) Oral ethanol selfadministration in rhesus monkeys: behavioral and neurochemical correlates. Alcohol Clin Exp Res 23:1352-1361. 